\title{
Problem-Solving in a Case-Based Course: Strategies for Facilitating Coached Expertise
}

\author{
Donald A. Stepich \\ Peggy A. Ertmer \\ Molly M. Lane
}

This paper proposes the use of specific coaching strategies to facilitate student use of expert-like problem-solving strategies while analyzing and solving instructional design case studies. Findings from an exploratory study, designed to examine changes in students' problem-solving skills as they analyzed case studies, suggested that students could show expert characteristics at times, under some circumstances, but did not perform like experts on a regular basis. At two midwestern universities, 37 students analyzed 6 to 10 case studies both in class and in on-line discussions. Comparisons were made both within and across students, as well as across time, to examine patterns and changes in student problem-solving approaches. Findings suggested that primary influences on the incidence of expert performance were more external than internal and might be more aptly characterized as "coached expertise." Specific suggestions are included for coaching the development of student problem-solving skills within a case-based course.
Professional educators face a daunting challenge-preparing students to solve the kind of complex, ambiguous problems that they will encounter as practicing professionals. Unfortunately, we are not always successful in meeting this challenge. For example, in a study by Dahlgren and Pramling (1985), physicians noted the need to reorganize what they learned in medical school from a focus on content areas to a focus on common clinical problems. In addition, engineers and business administrators noted that the theories they learned in school were often too simplistic to help in solving real-life problems. Julian, Kinzie, and Larsen (2000) lamented that "novice [instructional] designers frequently enter the workforce with an understanding of the ID [instructional design] process but without the knowledge base that can help them solve instructional design problems and develop solutions" (p. 165).

Increasingly, professional educators have turned to the use of cases in an effort to help students learn to approach problem situations in the same ways that practicing professionals do. Case-based instruction presents students with a recreation of a complex situation (a case) and asks them to analyze and solve the problems through reflection and discussion (Allen, Otto, \& Hoffman, 2000). In case-based instruction the learning focus shifts from the explicit knowledge and skills that form the traditional academic curriculum to the development of active knowledge-what Whitehead called "wisdom" (1929). Active knowledge goes beyond simply recalling information to the ability to use that information to select relevant issues and solve identified problems. For example, students in 
law school will read a case study and participate in a dialogue designed to elicit the key issues and legal principles in the case. More than simply recalling information, the students are asked to analyze the situation as a practicing lawyer would (Williams, 1992). Similar methods have been used in both business and medical education for nearly 100 years (Albanese \& Mitchell, 1993; Christensen, 1987).

Case-based instruction offers a number of advantages for professional education. Cases are thought to be more effective than didactic teaching methods because they (a) more accurately represent the complexity and ambiguity of real-life problems, (b) provide a framework for making explicit the problem-solving processes of both novice (student) and expert (instructor), and (c) provide a means for helping students develop the kind of problem-solving strategies that practicing professionals use (Julian et al., 2000). More specifically, we postulate that case-based instruction can help students adopt the characteristics of expert problem-solvers by helping them:

- Focus on the big picture. Expert problem solvers typically conceptualize a problem in terms of an appropriate underlying principle while novices tend to represent the problem in terms of surface features (Bruer, 1993). In case-based instruction, knowledge is embedded within complex and ill-structured problems. As a result, students have an opportunity to practice "spotting" the underlying issues and principles in authentic, relevant problems.

- Work forward from what they know. Experts often build on what they know, generating hypotheses and looking for information to test those hypotheses (Johnson, 1988). In contrast, novices tend to focus on what they do not know, looking for information to fill in the gaps. A case study, by necessity, presents an abbreviated view of a problem situation. Students are forced to do the best they can with the information that is available. Thus, they learn to frame problems in ways that will move them forward toward a solution.

- Simultaneously consider multiple factors. Experts are likely to consider the web of relationships and interactions that exist in the problem situation, while novices generally consider one factor at a time (Perez \& Emery, 1995). Cases allow students to experience the "complex and dynamic forces" (Rowland, 1992) that operate within the kind of complex problems that professionals commonly encounter. Although individual students may initially focus on a single factor when analyzing a case, case discussions tend to bring all of these factors to the table. This, then, facilitates consideration of all factors in an interdependent manner.

- Generate tentative solutions. Both experts and novices generate solution ideas early in the problem-solving process. However, experts are more likely to modify or eliminate those solutions as additional information becomes available (LeMaistre, 1998). Case studies tend to involve more than one key player, each representing a unique perspective. With practice, students can begin to understand that each player has a legitimate voice. Students are encouraged to modify their initial solutions as information accumulates and different perspectives are heard.

- Consider potential consequences and implications. Experts think through their recommendations more thoroughly than novices do, and consider how those recommendations might be implemented and what implications they might have (Rowland, 1992). As part of the case discussion, students are asked to consider the consequences of their recommended solutions and to select the one with the greatest benefits and smallest risk. Students and instructors are encouraged to evaluate each other's recommendations and to challenge decisions based on their assessment of the consequences for all case players.

Case-based instruction seems to be a natural fit with professional education in the field of instructional design. Like other professions, instructional design is a problem-solving enterprise in which practicing professionals combine creativity with technical skills to solve complex, ambiguous problems. Also like other professionals, instructional design educators are looking to bridge the gap between education and practice (Quinn, 1994; Rowland, Parra, \& Basnet, 1995) using a variety of methods, including case- 
based instruction (Ertmer \& Quinn, 1999). According to Julian et al. (2000), case studies can help instructional design students (a) draw connections between their emerging knowledge of instructional design and the complex demands of practice, (b) reflect on relevant theory and methods as they explore a greater number of design issues in a broader array of contexts, and (c) broaden their knowledge base as they collaborate with colleagues to identify effective design solutions.

In order to take advantage of the perceived strengths of case-based instruction, we developed an instructional design course in which the use of cases comprised our primary instructional method. Our original purpose was research. We planned to examine changes in student problem-solving skills during a course in which case-based instruction was used. However, after several different offerings of the course, we found that we had learned more about our use of cases than about changes in student problem-solving skills. That is, the changes in our application of case-based instruction appeared more substantial than changes in students' problem-solving skills. Furthermore, as we continued to modify and refine our casediscussion strategies, we began to identify techniques that seemed better able than others to facilitate expert-like responses among the students. Thus, we began to consider ways in which we might more purposefully coach our students as they developed their problem-solving skills.

The purpose of this paper, then, is to describe how our use of case-based instruction has evolved in response to our ongoing examination of the effectiveness of specific coaching practices. Recognizing that few guidelines exist for how to coach the development of student problem-solving skills using case-based instruction, this paper offers an initial set of recommendations, based on data gathered during three semesters of instruction (five different courses). The first section of the paper describes the context in which case-based instruction was situated, including the courses and the use of cases, as well as our data-collection and analysis methods. The second section offers a set of guidelines for using cases as an instructional method in the education of instructional designers. Specifically, we present coaching guidelines intended to help students use and develop the kind of problemsolving strategies commonly used by experts. Bracketed [ ] statements taken directly from electronic discussions are included throughout the paper to illustrate our procedures, results, and suggested coaching strategies.

\section{CONTEXT}

In the spring of 1998, the first two authors cotaught an advanced instructional design course at a large midwestern university. One faculty member was serving in a visiting position while on sabbatical leave from another institution. The following two spring semesters (1999 and 2000), both instructors taught similarly structured courses at their respective universities. During the spring 2000 semester, the two courses shared an on-line bulletin board that allowed students to participate in shared electronic discussions.

Participants $(N=37)$ were enrolled in advanced graduate $(n=25)$, introductory graduate $(n=7)$, or advanced undergraduate courses $(n=5)$ in instructional design. As noted earlier, students participated during one of three semesters: spring $1998(n=7)$, spring $1999(n=12)$, or spring $2000(n=18)$. Table 1 illustrates the distribution of students by semester and by the type of course in which they were enrolled.

Graduate students were enrolled in either an advanced instructional design course within an educational technology program or an introductory course within a human resource develop-

\begin{tabular}{cccc} 
Table $1 \quad \square$ & Distribution of Participants Across \\
Courses and Semesters \\
\hline & $\begin{array}{c}\text { Advanced } \\
\text { Under- } \\
\text { graduate }\end{array}$ & $\begin{array}{c}\text { Introductory } \\
\text { Graduate }\end{array}$ & $\begin{array}{c}\text { Advanced } \\
\text { Graduate }\end{array}$ \\
\hline $\begin{array}{l}\text { Spring } \\
1998 \\
\text { Spring } \\
1999 \\
\text { Spring } \\
2000\end{array}$ & - & - & 7 \\
& - & - & 7 \\
\end{tabular}


ment program. Students in the advanced course had taken 0-7 previous instructional design courses. Although an introductory instructional design course was listed as a prerequisite, three students were admitted without the introductory course, having gained sufficient foundational knowledge from previous work experiences. Graduate students ranged in age from 24-51 years, with an average age of 35 years. Undergraduate students were enrolled in the second instructional design course within a human resource development program. Undergraduate students ranged in age from 21-24 years, with an average age of 23 years.

\section{PROCEDURES}

Students in each course analyzed 6 to 10 instructional design cases as part of their course assignments. Case studies were drawn from Ertmer and Quinn (1999) and were used in conjunction with other activities (guest speakers, student presentations, project assignments, required readings) throughout the semester. There were no assigned textbooks in the advanced graduate course although additional readings were frequently recommended or required. The introductory graduate course included an instructional design book by Smith and Ragan (1999); the undergraduate course used a text by Kemp, Morrison, and Ross (1996).
Students participated in case discussions both in class and on-line. On-line discussions were facilitated via a "listserv" or a Web-based (World Wide Web) bulletin board and typically preceded the in-class discussions. While the listserv discussions extended dialogue among the advanced ID students only (spring 1999), the Web-based discussions included students enrolled in the introductory and advanced courses at both universities during spring 2000. Various techniques were used to initiate and facilitate the discussions, including debate, role play, and structured discussion. Regardless of technique, each discussion revolved around one or two basic tasks: (a) analyzing the problems and issues in the case and (b) recommending solutions for identified problems and issues.

Qualitative analysis methods were used to examine student responses to each case study. Student responses were coded using the five problem-solving characteristics abstracted from the literature on expert-novice differences (described briefly in Table 2 and more completely in Appendix A).

We read each student's response and classified it as either expert-like or novice-like on each characteristic. As much as possible, each characteristic was considered independently. That is, a student's response could be expert-like on one characteristic and novice-like on another. To increase the consistency of our classifications, we identified statements within the student

Table $2 \square$ Categories Used to Code Student Case Responses

\begin{tabular}{|c|c|c|}
\hline Problem-Solving Strategy & Expert & Novice \\
\hline $\begin{array}{l}\text { Conceptualization of } \\
\text { the issues }\end{array}$ & $\begin{array}{l}\text { Interprets issues in light of } \\
\text { previous experience }\end{array}$ & Reports issues as given \\
\hline Search for information & $\begin{array}{l}\text { Focus is on building from } \\
\text { what is known }\end{array}$ & Focus is on filling in what is not known \\
\hline $\begin{array}{l}\text { Attention to relationships } \\
\text { among factors }\end{array}$ & $\begin{array}{l}\text { Makes explicit links among } \\
\text { multiple factors }\end{array}$ & $\begin{array}{l}\text { Lists issues without apparent } \\
\text { consideration for how they might } \\
\text { be related }\end{array}$ \\
\hline $\begin{array}{l}\text { Level of commitment } \\
\text { to solutions }\end{array}$ & $\begin{array}{l}\text { Recommendations are described } \\
\text { in tentative terms and are } \\
\text { subject to change as additional } \\
\text { information becomes available }\end{array}$ & $\begin{array}{l}\text { Recommendations are described in } \\
\text { definite terms and are unlikely to } \\
\text { change as additional information } \\
\text { becomes available }\end{array}$ \\
\hline $\begin{array}{l}\text { Consideration of } \\
\text { implications of } \\
\text { recommendations }\end{array}$ & $\begin{array}{l}\text { Includes explicit consideration } \\
\text { of implementation and/or } \\
\text { effects of recommendations }\end{array}$ & $\begin{array}{l}\text { Little apparent consideration of } \\
\text { implementation and/or effects of } \\
\text { recommendations }\end{array}$ \\
\hline
\end{tabular}


responses that seemed to clearly illustrate expert and novice responses for each characteristic (see Appendix A). These examples were then used as templates to guide our continued analysis efforts.

Throughout the data analysis process we continued to refine our definitions of these codes, using the constant comparison method (Lincoln \& Guba, 1985). As we read each student response, we compared it to our existing templates and, at the same time, reflected on the meaning of the categories. The result was that we were constantly clarifying our understanding of these expert-novice characteristics and how they were represented in student responses, selecting new and better examples to illustrate the categories, and modifying our definitions of the categories to fit the emerging themes and patterns.

\section{RESULTS}

In general, students showed both novice-like and expert-like responses throughout the semester. Furthermore, this pattern held true despite wide variations in students' ages, previous experiences, and current level of study (graduate vs. undergraduate). In fact, it was not unusual for students to demonstrate a more expert-like response on an earlier case and a more novice-like response on a later case. For example, we noted that when students' attention was specifically directed to the potential implications of a solution, students were able to consider the effects of their recommendations, but they did not always do so on their own. As another example, when students were asked to classify one or several issues in a case, their conceptualizations tended to take on a big-picture approach. In contrast, if asked to simply describe the issues, students tended to respond with more surface-level reporting.

As we began to consider potential reasons for the uneven development and demonstration of student problem-solving skills, our research focus shifted from an emphasis on what students could or could not do, to what we, as the instructors, did or did not do in our role as coaches. In an attempt to explain our "uneven" results, we reexamined our on-line case discussions to identify if, and how, specific coaching strategies may (or may not) have supported student performances relative to each of the five characteristics of expert problem-solving (a. focusing on the big picture, $\mathrm{b}$. working forward from what they know, c. simultaneously considering multiple factors, $d$. generating tentative solutions, and e. considering potential consequences and implications). While acknowledging that these discussions represented only a subset of our data (albeit a readily available subset), we found that these on-line archives provided fruitful opportunities for our retrospective examination of the relationships among coaching strategies and student problem-solving approaches.

In the section that follows we describe the specific coaching strategies we used to initiate the on-line case discussions with the 18 students enrolled during spring 2000. Although we recognize that coaching can, and does, occur throughout a case debriefing, our discussion here focuses primarily on the case set-up as a critical starting point. Specifically, we examined the extent to which two expert problem-solving characteristics, (a) conceptualizing the issues in the case and (b) considering the impact of recommended solutions, were facilitated by the use of specific coaching strategies. Given the preliminary nature of these analyses, we judged that these two characteristics offered a useful starting point. Because these categories were fairly well defined, identification and classification of students' responses could be made somewhat more reliably. In the next section, we describe student responses to five different case set-ups:

1. Structured discussion

2. Debate

3. Reflective practitioner

4. Role play

5. Discussion chain

Each technique is considered in turn. ${ }^{1}$

1 Throughout the following discussion, participants in the ID courses are referred to as "students," whereas those who are receiving instruction within the case narratives are referred to as "learners." 


\section{Structured Discussion}

We used a structured discussion to initiate the on-line discussion for the Frank and Semra case. In this case, two U.S.-based instructional designers are faced with the challenge of developing a new curriculum to teach instructional design to trainers who work for the government of a southeastern Asian country. To begin, the instructors provided a one-sentence summary of the case, followed by three specific questions: (a) What do you think the learners' expectations of the new curriculum will be; (b) what kinds of adjustments do you think the learners will have to make; and (c) how might you facilitate these adjustments? Students were not asked, specifically, to discuss either the underlying issues in the case or the impact of their solutions.

Conceptualization of the case issues. As the first on-line discussion of the semester, this discussion starter seemed to lead to fairly structured responses. Almost every student $(n=16 / 18)$ answered each of the three questions, one by one. Perhaps because this set of questions seemed so structured, most of the students (10 of the 16 who responded to this question) started by reporting or summarizing the facts in the case. However, even though the primary focus of the students seemed to be on reporting, 12 students included an interpretation of the case events, either separately or in conjunction with fact reporting ["The learners need to see a need for change before they buy into a new system of design"] ["This is similar to a change initiative"].

Interestingly, our efforts to help students broaden their initial conceptualizations met with little success. Questions we asked during the discussion to explore the identified issues ["What is it about the culture issue that Frank and Semra should adjust to?"] did not generate any direct responses from the students. However, when another student asked whether the case provided sufficient reason to believe that a change should be made in the training methods being used (a common recommendation), other students added new interpretations of the issue ["Who is the client here? Who has the right to decide what is or isn't appropriate?"]. This difference in student responses to instructors and peers may have been related to the timing of the case. Because this was the first case, students may have felt some discomfort with this type of on-line environment or with responding to the instructors as participants in the discussion.

Student consideration of the impact of recommendations. The three questions that opened the discussion asked students to make recommendations but did not ask them to explain the impact or implications of those recommendations. Additionally, the instructors asked few followup questions during the discussion and those that were asked generally focused on recommendations rather than implications ["Any thoughts about what Frank and Semra might do to make sure that it goes well with these trainers?"]. In retrospect, there were opportunities during the discussion to ask the students to explore implications (perhaps using questions such as "What effect might that have on the current trainers?") but, unfortunately, we did not take advantage of these opportunities.

Predictably, students provided recommendations, often stated in specific terms ["I should convince them that the system approach is effective"] ["I will look for new or young trainers"]. However, there was little consideration of the implications of those recommendations. When students did consider implications, they were typically limited to a narrow focus on how a recommendation would solve the identified problem ["Once the interactive atmosphere is established, the losing-face problem will not exist anymore"]. Little apparent thought was given to the broader impact of a recommendation, such as how it might affect other participants within the case or fit with other recommendations.

\section{Debate}

We facilitated an on-line debate, the Denny Clifford case, about a design consultant with a traditional instructional systems background who is hired by a science educator (Cynthia Oakes) to create constructivist learning materials. As part of the set-up for this discussion, the instructors provided the following conceptualization: "This 
case raises some important questions about working with clients who view things quite differently from us." Students were then asked to argue whether or not an instructional designer should accept such an assignment. Students were assigned to one of the two positions and encouraged to engage in some "friendly competition."

Conceptualization of the case issues. In response to this set-up, almost every posting represented a conceptualization of why Denny should or should not take this job. Students were forced to support their positions, which led to a variety of subconceptualizations of the issue. Some students argued in terms of comfort or stress issues; others argued in terms of risk, challenge, or growth possibilities. Because of this set-up, few students felt the need to cite facts from the case. Almost all students interpreted the case from the point of view they were assigned. The debatestyle set-up seemed to be an effective way to get students to think beyond the facts of the case to the positive and negative sides of an issue. In addition, by providing a primary issue to "chew on," the instructors modeled how to conceptualize issues in a case.

Student consideration of the impact of recommendations. The debate format appeared somewhat successful in helping students focus on implications, especially among students who argued the yes position. Students explored implications from both a present and future perspective. In terms of present implications, some students noted that accepting the assignment would require additional work for both designer and client ["He may need to do a little extra work"] ["She may have to play a larger role in the process ..."]. Other students included suggestions for increasing the likelihood of success on the assignment ["Perhaps Denny needs to talk to the people using Oakes' methods and find out how they are actually using them"] ["First, he can begin by identifying the aspects that he has in common with Oakes ..."]. In terms of future implications, some noted that accepting the assignment would help the designer develop his career ["Working with Oakes ' could open up even more doors ..."] ["If he begins to limit his range of content and philosophies as a designer, he will be compromising his career"].

\section{Reflective Practitioner}

A reflective practitioner set-up was used with the Michelle Nguyen case. Michelle Nguyen is a designer-programmer working for a large medical center. She encounters a number of surprises as she prepares to roll out a new product, carefully designed to reflect the requirements of a front-end analysis completed nine months earlier. To begin this on-line discussion, students were asked to assume the role of the instructional designer in the case, and, as a reflective practitioner, consider lessons learned from the specific experience. Rather than placing blame on various stakeholders, students were encouraged to move beyond simply describing what happened, to reflecting on what would be an important thing to do, or not do, the next time.

Conceptualization of the case issues. A reflective practitioner set-up forced students to prioritize the important lessons learned from the case. This took them beyond facts, to their own interpretation of the important issues. For example, some of the lessons learned included the need for continual communication, revisiting steps in the ID process as you go along, and having a backup plan for dealing with problems. The lessons-learned approach seemed to help students conceptualize the primary issues in the case in terms of important design processes and procedures.

Consideration of the impact of recommendations.

The students explored the implications of their original lessons more in this discussion than in previous discussions. In addition, the specificity of the instructors' follow-up questions seemed to have an effect on the discussion that followed. For example, relatively general questions ["How do you think a focus group might have been helpful in this case?"] resulted in few responses from the students. In contrast, questions that were more specific ["But since a learner analysis had already been done, wouldn't this slow down progress on the project...?"] resulted in a 
discussion that involved as many as 12 different responses from the students.

\section{Role Play}

In two different case discussions, students were assigned roles to play and asked to view the case from that person's perspective. In the Haley Lawrence case, students were assigned a role for on-line discussion and asked to "get inside the person's head" and identify his or her issues and concerns. Haley Lawrence is a case involving a variety of stakeholders within a client organization. Although Haley is hired to help the organization develop training materials for their sales representatives, she encounters several people in the organization who appear uncertain about her role and who find her presence threatening.

The Andrew Stewart case deals with the complexities of integrating the contributions of different groups of stakeholders involved with a large design project. A secondary focus is on planning and completing a formative evaluation for a product that is still being developed. The case ends with the team in "crisis mode" as a deadline looms and the information collected to date is unacceptable. In the Andrew Stewart case, students were assigned a role and asked to consider what they would do differently if they could start over, and what they would do now, given the situation as it is.

Students were more active in these two discussions than they had been earlier, possibly because they had participated in several previous case discussions, but perhaps also because of the safety of playing a role. Students could express themselves more directly and emphatically because, presumably, they were expressing the views of a character in the case. One result is that both discussions included virtual arguments between role players ["To be honest with you, Mr. Sumida, you're changing the work contract on me." "Ms. Lawrence, you were brought in the picture to solve a problem not to create new ones."] ["It was not me who was trying to create new tasks. Instead I was trying my best to focus my tasks on our original contract"]. Students tended to stay in character throughout the discussion, often responding to one another in the first person ["Why should these be my problems?"] [“Don't put me in a bind"].

Conceptualization of the case issues. Despite an involved and intense on-line discussion, the Haley Lawrence role-play appeared only mildly successful at helping students frame and address design issues in the case. While students may have considered how one individual perceived the issues in the case, they did not work very hard, if at all, to understand each other's issues. Students enjoyed playing personalities, as noted earlier, but did not seem to move outside the personalities to consider broader case issues. However, in the students' defense, they participated in this discussion exactly as they were instructed. Had we encouraged them, sometime during the discussion, to switch hats with another stakeholder, we might have been more successful in moving beyond personalities to issues.

The second role-play set-up was primarily solution oriented. Although students were assigned roles to play, they were told, right from the beginning, that they all shared responsibility for the current situation. Thus, students refrained from blaming others, and looked for ways to help salvage the situation. As the role players considered their own responsibilities in causing the situation, conceptualizations emerged ["I should not have involved a group that wasn't as motivated about this project as the others."] ["I think that the major flaw in what happened had to do with communication."] ["I should have been more professional"].

\section{Consideration of the impact of recommendations.}

Students did consider impact and implications in these discussions. On occasion, this included the practicalities of implementing suggestions that were made ["You can have the St. Louis team send back the manuals on a weekly basis"]. Typically, however, this was limited to a narrow view of how suggestions made by others affected their own roles ["Why should these be my problems?"] ["If you could show me a little respect..."]. Students seemed to have difficulty stepping outside of their assigned roles to see the situation more broadly or to acknowledge the perspectives of the other role players. 
Discussion Chain

For the Sandra Hernandez case, students were asked to structure their discussion in the form of a chain reaction. The Sandra Hernandez case describes how an instructional designer, Jake Spaulding, was asked to help Sandra "fix" problems she was having with her freshman engineering lab. In order to help Sandra, Jake must balance a number of contradictory requirements and work within numerous resource constraints. For this discussion, one of the instructors began the on-line discussion by describing what he saw as the most important issue and then proposed a solution. Students then were instructed to either agree or disagree with a posted comment. If they agreed, they had to add something to the comment; if they disagreed they had to pose a counter argument.

Conceptualization of the case issues. This type of set-up provided students with a model of how to conceptualize one issue in the case and then pose a relevant solution. By requiring students to add to each comment that they responded to, we forced them to consider other important issues that had been ignored or potential consequences of proposed solutions that had not been considered. Students looked for nuances in interpretation so that they could enhance or offer an alternative to a comment already posted ["I don't agree that time is the main issue. I believe the main issue is what will be the best approach to teach the class ... I'll consider time as one of many factors that are involved in the main issue"]. Thus, conceptualizations were more complex than in previous cases, and evidence was typically provided to support specific conceptualizations. It is important to remember that this discussion occurred late in the semester, which may partially explain the increased complexity of student responses.

\section{Consideration of the impact of recommendations.}

The ground rules inherent in this type of set-up encouraged the students to think directly about the implications of posted solutions. They could agree or disagree with a recommendation, but only after giving some thought to what benefits or limitations they could see. One result was that students seemed to take a relatively broad view of a recommended solution. Sometimes this took the form of adding suggestions about how to implement a solution. For example, one recommendation was to have the lab already set up for the learners. Students added their thoughts about how to make this work ["I can see this happening with the classes being divided into two sessions"]. Sometimes it took the form of pulling in other issues. For example, another recommendation was to conduct the lab activities via computer simulation. Students discussed this solution in terms of cost ["Although this seems like a good solution, it's expensive and time-consuming"] ["If you cost out 80 students per semester, it would not take long to make this program cost-effective"], access ["Are there computers available for all of the students to have access?"], and instructional methods ["From the case, it seems to me that the experiments are a very 'hands on' type of procedure. I think computer simulation is not good enough for this type of experience"]. In order to agree or disagree with another person's comment, students had to carefully consider the many implications of a recommended solution. This, then, led to a fairly sophisticated understanding of the impacts of any single solution.

\section{Summary}

In general, the problem-solving strategies used by students in our case-based courses did not show steady improvement from the beginning to the end of the semester. In fact, students showed both weak and strong responses to cases throughout the semester, suggesting that their problem-solving expertise was not internalized. They could show characteristics of expert problem-solvers at times, under certain circumstances, but did not do so on a regular basis. The primary influences on their case analyses appeared more external than internal, including the way the case discussion was set up by the instructors. 


\section{COACHING GUIDELINES}

In the previous section, we described the coaching strategies we used to initiate on-line case discussions and the results that followed their use. Specifically, we related these results to two expert problem-solving strategies: (a) the ability to conceptualize situations in terms of underlying principles rather than surface details, and (b) the ability to consider the impact and implications of recommended solutions in broad, rather than narrow, terms. In this section, we abstract from these results several strategies that instructors can use to guide their own coaching efforts. We have purposely described the strategies in broad terms in order to present strategies that can be applied through various techniques to cases in a variety of content areas. Where possible, we illustrate the strategies with examples from our case-based courses.

\section{Coaching Student Conceptualization of Case Issues}

Strategy 1: Structure the discussion by giving students an initial role to play or a position to take in the discussion. In our case discussions we used debate, role-play, and reflective practitioner formats, all of which worked reasonably well as a way of implementing this strategy. Besides supporting student conceptualization of the case issues, this strategy has several other benefits.

First, students can present observations and opinions within the context of an assigned role, and not feel as if they are exposing their own views to disagreement, ridicule, or evaluation. For example, during the on-line discussion of the Haley Lawrence case we asked students to play one of five characters in the case and to describe how that person viewed the case situation, including his or her issues and motives. Students used a variety of creative approaches to express the thoughts, feelings, and opinions of their assigned character. One student wrote in stream-of-consciousness form, which enabled other students to read this character's innermost feelings and thoughts about the case ["I can't believe Sumida didn't tell me about his task force and this list. ... When is Califano coming on board again? I can't wait until then, okay schedule an appointment with Katz . . ."]. Another student summarized her response in the form of a memo to another character. A third student set the scene and then began sharing his thoughts by talking to himself ["Sumida was smoking his last cigarette before going to bed, while reviewing a chapter of Covey's Seven Habits of Highly Effective People. He flipped over the open book on the table and he paused into thinking about his last meeting. The meeting scene was in front of his eyes; he started talking to himself and creating his own scenarios about the new project"]. The safety of responding from the perspective of an assigned role appeared to give students permission to respond both boldly and creatively, without fear of being criticized by their peers.

Second, the assigned role or position gives students some initial guidance and parameters that help them form their initial response. For example, when we began discussing the Denny Clifford case we asked students a single question: "The first question that needs to be addressed is whether it's even possible to design instruction for someone whose philosophy is diametrically opposed to our own-and when we don't really understand that other philosophy." We then asked half of the students to "present reasons why Denny should not try to work with Cynthia" and the remaining students to "present reasons why Denny should be successful working with a client with a different philosophy." The assigned position enabled students to engage in a lively debate as they argued both why Denny should take the job ["My opinion is that Denny Clifford should 'say yes bravely' to taking this job especially because he should remind himself that he is an independent consultant for a reason ... that he must try to continually learn different philosophies of education so that he is able to innovate more instructional designs"] and why he should not take the job ["My position is that Denny Clifford should just say no to taking this job. He reminds himself that he is an independent consultant for a reason ... that he can choose the jobs he wants to work on"]. In addition, being assigned a position that one did not necessarily agree with encouraged students to consider strong arguments from 
both sides of the issue. This, then, provided them with a more complete view of the situation, allowing them to see that there were advantages and disadvantages to either decision the designer might make.

Third, assigning different roles within a single discussion ensures that the viewpoints of different case players will be voiced. This results in a broader view of the case. Following this, additional questions can be posed to compare and contrast the conceptualizations or interpretations of the case represented by the multiple roles. Returning to the Haley Lawrence case, each student played the role of one of the five characters in the case, which meant that several students were playing the same role during the discussion. Therefore, each character in the case had at least one voice in the discussion. During the discussion, the instructors can also help students move beyond their own role to see the viewpoints of the other characters ["So what exactly do you think is motivating his actions? And how can Lawrence get through to him and everyone else?"]. However, this may need to take the form of explicit directions, as the students in our courses did not seem inclined to do this on their own.

Strategy 2: Begin the discussion with a structure, but avoid rigid adherence to that structure. The instructor has two basic tasks in the case discussion: (a) setting up the discussion to create a dialogue among the students and (b) facilitating the discussion to keep the dialogue going. A flexible discussion structure helps with both of these tasks.

The case set-up helps to "prime the pump" by providing students with an initial shared framework for thinking about the case and expressing their thoughts. For example, in the discussion-chain approach used for the Sandra Hernandez case we started the chain by first making a statement, then asking an open-ended question, and finally presenting a set of ground rules for subsequent discussion. Specifically, one instructor began the chain:

[I think the biggest problem here is the students' backgrounds. They just aren't ready for this course. To solve this problem, I think Jake should find a way to simplify the content of the course so that it is more in line with the academic background of the students coming into the course. What do you think? If you agree, you must add to the posted comment in some way. If you disagree, you must offer an alternative of some kind.]

By including both guidelines and an example of how to follow the guidelines, we jump-started the discussion and made it easy for others to jump in.

Once the discussion starts and the ideas are flowing, the initial structure has served its purpose. In fact, students sometimes find it more constraining than facilitating. The instructor's tasks at this point are to help the students find the connections among the points being made and relate their discussion to the big-picture issues in the case. For example, during the discussion of the Denny Clifford case, one student suggested an analogy to support her point. There were different interpretations of the analogy, which lead to a digression in the discussion. One of the instructors maintained and refocused the dialogue by looking beyond the analogy and posting a question ["Christie's comment brings up ... two good questions: (a) Do you have to understand a philosophy in order to design instruction to teach that philosophy; (b) Do you have to subscribe to the philosophy in order to design instruction to teach that philosophy?]. In maintaining the flow of the discussion, it is important to remember that we want students to do more than just talk; our primary goal is to maintain a focused discussion that continues to address the issues in the case.

\section{Coaching Student Consideration of Implications of Solutions}

Strategy 1: Ask specific questions and limit the number that you ask at one time. During the initial set-up, it is possible to ask students to identify a problem, suggest a solution, and describe the possible impact of that solution. However, this may be too much for the initial set-up. It may be easier and better to explore these issues separately as the discussion progresses. When the initial set-up is too restrictive students do not have room to express their views and may feel that they are providing "answers" rather than 
discussing ideas. Once the discussion is going, however, students can more readily respond to specific questions about the impact of their recommendations on case stakeholders.

A multipart initial question may overwhelm students, especially if it appears to require specific answers. For example, we began the discussion of the Frank and Semra case with three specific questions, described earlier. The students were slow to respond to these questions, reporting that they felt overwhelmed by the number of questions and that they were concerned about posting correct answers. In contrast, we began the discussion of the Andrew Stewart case by asking the students to discuss two questions from their character's perspective: (a) If you had to do it over again, what would you do differently? (b) Now that you're in the pickle you are in, what will you do next? This technique enabled students to jump into the discussion without feeling as if they were overwhelmed or had to come up with the right answer. A result was that students joined the discussion more quickly and freely ["I obviously should not have tried to involve a group that wasn't as motivated about this project as the other participants ..."] ["If I had to do it over again, I suppose I should have reacted to my gut instinct when I saw the St. Louis team making faces. I'd forgotten how some designers think they know it all as soon as they land a nice paying job right out of school ..."]. It is important to pay close attention to the manner in which a case discussion is opened; concern over correct answers is likely to stifle participation.

Asking specific questions throughout the discussion encourages students to:

- Respond to one another's problem identification

- Suggest a solution to a problem described by someone else, or

- Describe the impact/implications of a recommendation made by someone else.

For example, throughout the Sandra Hernandez case students actively responded to one another's answers using the discussion-chain approach and offered alternative perspectives on the impact and implications of the case. Students often responded directly to a person and posed additional questions ["Your consideration about the limited budget available is nice, but how could students 'collect data' without conducting real experiments or computer simulations?"] ["I still disagree. How will the students conduct the experiments if the equipment isn't set up? Will the students still set it up? If they do then the diagrams may use even more valuable time when the students study them"]. Having permission to disagree with each other's interpretations allowed for a rapid exchange of comments, each providing a new consideration of possible impacts.

Strategy 2: Look for opportunities to join the discussion, but participate carefully. As the discussion progresses, the instructor's primary responsibility is to maintain the dialogue. To do this, it is important to continually look for opportunities to add questions and comments designed to help students see connections-to other students and to the big ideas that frame the case. At the same time, it is important to monitor the possible effects that your input may have on students. Students sometimes perceive comments from the instructor as the answer, which may impede, rather than support, the dialogue. In these situations, it is often better to resist the natural tendency to add your own more expert views, and let the students come to their own understanding of a case and its solution. Of course, this does not mean that instructors should avoid participating in the discussion. It means only that instructors should be constantly aware of the potential effects that their participation may have.

The instructor can model expert responses to give the students a clearer picture of what is required of them. For example, in response to an ongoing discussion of the Michelle Nguyen case, one instructor wrote:

[Playing devil's advocate, even if Michelle had conducted monthly (or quarterly) meetings with Alex and Susan, she still might not have found out soon enough about the library hours not being sufficient. I mean when is soon enough when you're creating CBI [casebased instruction]? And maybe the library hours aren't the real issue .... So the question I have is-do you think this case primarily illustrates a front-end analysis problem or an implementation problem? Ideas, anyone?] 
This comment was an example both of considering the implications of a recommendation that had been made (monthly meetings) and looking for the underlying principle ("Do you think this case primarily illustrates a front-end analysis problem or an implementation problem?"). Also, by prefacing the comment with the warning, "playing devil's advocate," the instructor signalse that the students' previous comments are not being criticized. In this way, students are encouraged to think about the issues in ways they previously had not considered.

The instructor's comments and questions can also encourage students to elaborate their thoughts about a point raised in the discussion. Other students can, then, respond to the elaboration, thereby continuing the dialogue. For example, during the discussion of the Haley Lawrence case, we commented on one student's reaction by posing additional questions for students to explore ["So what exactly do you think is motivating his actions? And how can Lawrence get through to him (and everyone else?)"]. When instructors participate carefully, through questions and comments, students' problemsolving approaches may incorporate more expert-like characteristics, including the consideration of the impact of initial recommendations.

\section{LIMITATIONS}

We began this work with the idea of identifying patterns in the development of student problemsolving skills. What we found, however, was an absence of patterns and, over the course of several semesters, our focus shifted to examining the coaching strategies we were using. In the previous section, we suggested several broad strategies instructors can use to guide their coaching. The strength of these suggestions, however, is limited, not only by our relatively small number of participants, but by several other factors, including: (a) analysis codes and categories that may not have been sophisticated enough to find patterns in student problem-solving skills, (b) external variables that were insufficiently controlled or accounted for in the study, and (c) insufficient time allotted for student problem-solving skills to develop. These limitations provide useful opportunities for future research.

One of the unstated goals of our initial investigation was to develop and apply an analysis framework for examining student responses to discipline-related case studies. The framework developed during this research, although greatly refined from its initial stages, must still be considered preliminary. Additional refinements are needed to allow consistent application while analyzing student case responses.

This study was not designed to identify cause-and-effect relations. However, in trying to make sense of the variability in students' case responses, we specifically focused on our use of different coaching strategies. Still, any number of uncontrolled variables, including different instructors and different levels of students, as well as their different background experiences, may have influenced student responses. Future research might verify the influence of these and other factors on the development of student problem-solving skills.

The development of problem-solving expertise is known to take place over a long period of time. Trying to capture this development in a semester-long course is difficult, at best. Longitudinal studies are needed to determine if, and how, this process occurs over an extended period of time, and the extent to which instructors can influence that process through the coaching techniques they use during case discussions. Furthermore, it is important to determine the extent to which students who develop strong problem-solving skills within case-based courses actually transfer these skills to their future jobs. Does the experience of solving cases in a college course benefit instructional designers in their future practice? Further research is needed to address these important questions.

\section{CONCLUSION}

Case-based instruction has been heralded as a powerful means for helping instructional design students bridge the gap between novice and expert practice (Julian et al., 2000). However, case-based instruction does have its risks. Stu- 
dents may like using cases and perceive that they have learned a lot. But this does not necessarily mean that they have gained new or better problem-solving skills that will help them become better instructional designers. Blumenfeld et al. (1991) suggested that "without adequate attention to ways of supporting students and teachers, learning-by-doing will not be done" (p. 374). Case-based instructors need effective strategies for supporting students during case study analysis. If not used well, cases may merely perpetuate the approaches and strategies that students already use. Clearly, teaching with cases is not an easy task. As noted by McNergney (1999): "Teaching and learning with cases is not for the faint of heart" (p. vi).

Sykes and Byrd (1992) stated that "learning from cases will depend on the interaction among what the case presents, what the reader brings, and what the teacher does with the case" (p. 511). Shulman (cited in Lundeberg, Levin, \& Harrington, 1999, p. 15) expressed the importance of discussion and facilitation when she noted, "cases, even with commentaries, do not teach themselves." The role of the coach (instructor) is viewed as being critical to the success of the entire process. Yet, there are very few guidelines available for instructors who wish to begin using a case-based approach. With little guidance, instructors can easily fall into the trap of thinking that just because case discussions are interesting and engaging, students are learning the things they need to learn to become better designers.

Through our ongoing examination of student responses to the use of cases, we have identified techniques that appear effective in eliciting student use of effective problem-solving strategies. Although our results are preliminary, this work addresses two important questions about the use of cases in instructional design courses:

1. What should we use as evidence of students' learning in a case-based course? and

2. How can we achieve specific learning outcomes (e.g., increase in problem-solving skills) through the use of specific coaching strategies?

To date, little work has been done to actually measure changes that occur in students' problem-solving skills through participation in a case-based course. Even less work has been done to tie specific coaching strategies to the attainment of those outcomes. This work represents the first step in addressing these important issues. Still, we realize that there is much more to learn. We plan to continue to examine specific coaching strategies that facilitate student problem solving within case-based courses. In addition, we plan to continue to hone our analysis skills so we can more readily examine the effectiveness of different coaching strategies on the development of student problem-solving skills. Ultimately, by refining our case-coaching strategies, we increase the potential of case-based instruction to facilitate the development of expert problem-solving skills in our instructional design students.

Donald A. Stepich [d-stepich@neiu.edu] is with the

Department of Educational Leadership and

Development at Northeastern Illinois University.

Peggy A. Ertmer [pertmer@purdue.edu] and Molly

M. Lane [lanemm@purdue.edu] are with the

Department of Curriculum and Instruction at Purdue University.

The authors gratefully acknowledge the support provided by grant \#2-30906 from the Northeastern Illinois University Committee on Organized Research.

\section{REFERENCES}

Albanese, M.S., \& Mitchell, S. (1993). Problem-based learning: A review of literature on its outcomes and implementation issues. Academic Medicine, 68, 52-81.

Allen, B.S., Otto, R.G., \& Hoffman, B. (2000). Casebased learning: Contexts and communities. In $\mathrm{S}$. Tobias \& D. Fletcher (Eds.), Training and retraining: $A$ handbook for business, industry, government, and the military (pp. 443-471). Englewood Cliffs, NJ: Prentice Hall.

Blumenfeld, P.C., Soloway, E., Marx, R.W., Krajcik, J.S., Guzdial, M., \& Palincsar, A. (1991). Motivating project-based learning: Sustaining the doing, supporting the learning. Educational Psychologist, 26, 369-398.

Bruer, J.T. (1993). The mind's journey from novice to expert. American Educator, 17(2), 6-15, 38-46.

Christensen, C.R. (1987). Teaching and the case method. Boston: Harvard Business School.

Dahlgren, L.O., \& Pramling, I. (1985). Conceptions of knowledge, professionalism, and contemporary problems in some professional academic subcultures. Studies in Higher Education, 10(2), 163-173.

Ertmer, P.A., \& Quinn, J. (1999). The ID CaseBook: Case 
studies in instructional design. Englewood Cliffs, NJ: Prentice Hall.

International Board of Standards for Training, Performance, and Instruction (IBSTPI, 1984). Instructional design: The standards. Washington DC: Author.

Johnson, S.D. (1988). Cognitive analysis of expert and novice troubleshooting performance. Performance Improvement Quarterly, 1(3), 38-54.

Julian, M., Kinzie, M.B., \& Larsen, V.A. (2000). Compelling case experiences: Performance, practice, and application for emerging instructional designers. Performance Improvement Quarterly, 13(3), 164-201.

Kemp, J.E., Morrison, G.R., \& Ross, S.M. (1996). Designing effective instruction (2nd. Ed.). Upper Saddle River, NJ: Merrill/Prentice Hall.

LeMaistre, C. (1998). What is an expert instructional designer? Evidence of expert performance during formative evaluation. Educational Technology Research and Development, 46(3), 21-36.

Lincoln, Y., \& Guba, E. (1985). Naturalistic inquiry. Thousand Oaks, CA: Sage.

Lundeberg, M.A., Levin, B.B., \& Harrington, H.L. (Eds.) (1999). Who learns what from cases and how? The research base for teaching and learning with cases. Mahwah, NJ: Lawrence Erlbaum.

McNergney, R.F. (1999). Foreword. In M.R. Sudzina (Ed.), Case study applications for teacher education: Cases of teaching and learning in the content areas (pp. v-vi). Boston: Allyn and Bacon.

Perez, R.S., \& Emery, C.D. (1995). Designer thinking: How novices and experts think about instructional design. Performance Improvement Quarterly, 8(3), 8095.

Quinn, J. (1994). Connecting education and practice in an instructional design graduate program. Educational Technology Research and Development, 42(3), 7182.

Rowland, G. (1992). What do instructional designers actually do? An initial investigation of expert practice. Performance Improvement Quarterly, 5(2), 65-86.

Rowland, G., Parra, M.L., \& Basnet, K. (1995). Educating instructional designers: Different methods for different outcomes. In B.B. Seels (Ed.). Instructional design fundamentals: A reconsideration. Englewood Cliffs, NJ: Educational Technology Publications.

Smith, P.L., \& Ragan, T.J. (1999). Instructional Design (2nd. ed.). Upper Saddle River, NJ: Merrill/Prentice Hall.

Sykes, G., \& Bird, T. (1992). Teacher education and the case idea. Review of Research in Education, 18, 457-521

Whitehead, A.N. (1929). The aims of education: And other essays. New York: Macmillan.

Williams, S. (1992). Putting case-based instruction into context: Examples from legal and medical education. Journal of the Learning Sciences, 2, 367-427. 


\section{Appendix A $\square$ Descriptions of Coding Categories}

1. Conceptualizations of the issues (interpreting vs. reporting)

When confronted with a "messy" problem situation, experts will use their own experience to inform their views of the case and to reframe the problem, often using their own words. Experts are likely to identify the "central" issue in a case or to categorize or prioritize the issues in some way, often including an explanation of the principle underlying the priorities (Bruer, 1993). The result is an interpretation of the case that is often unique and specific to the situation.

Example: "I am basing my remarks on the productivity issue because I think in a manufacturing environment it all boils down to $\$$. And I also think that to have any credibility as an instructional designer, you have to show that you understand how training and your role as a designer can impact the productivity."

In contrast, novices are likely to report or summarize the issues, as they are described in the case. The report is often verbatim and appears to take the problem(s) presented in the case at face value with little apparent effort to consider the extent to which the presented problems are at the "heart" of the case. The result is a simple recounting of issues, as others see them, that often remains at a superficial level.

Example: "Jim Huggins just received word that the multi-million dollar CBT program, which he proposed and designed, has failed:

- Only about $15 \%$ of the target audience used the CBT on a regular basis

- Engineers are more inclined to ask local experts for help rather than consult the CBT

- Process development leaders, who relied heavily upon the CBT to distribute information, were disappointed to find that their information was not getting out to the whole company."

2. Searches for information (present information vs. absent information)

When confronted with an ill-defined problem, both experts and novices recognize that they have incomplete information. However, experts typically focus on what they do know. They will make inferences based on available information and consider scenarios that are likely to emerge as more information is obtained (Johnson, 1988). In addition, they tend to take a more focused approach to information gathering. That is, they will look for specific information that will help confirm or refute their interpretations or assess the effectiveness of their proposed solutions.
Example: "If the problem is that the employees are not wearing proper safety equipment...

The second reason might be the lack of proper training...

The third reason that there might be an increase in accidents is due to the increase in production ..."

In contrast, novices tend to focus on what they don't know and to ask questions designed to fill the perceived information gaps. In doing so, they seem to lose sight of what they do know, suggesting that a great deal of additional information is necessary before a solution can be developed. In addition, their approach to information gathering often seems scattered. That is, they suggest additional information without apparent consideration for the specific purpose or value of that additional information.

Example: "In regards to an ID model, I find some of the key components are missing. For starters, Instructional Problems or Goals ... There is not research put into Learner Characteristics ..."

3. Attention to the relationships among factors (coherent plan vs. laundry list)

Both novice and expert problem solvers are likely to consider multiple factors in a case. However, experts are more likely to have a coherent plan. They may identify multiple issues, but are more likely to make explicit links among those issues (Perez \& Emery, 1995). Similarly, they may suggest multiple solutions, but link the suggestions together in a coordinated effort to solve the problem(s).

Example: "These problematic conditions need to be considered individually to determine if they are related to the person, the facility, the agency, COMET, or any combination of the four. Once that is done, then we must determine how those four (components) relate to the various other barriers as a whole."

In contrast, novices often take a "laundry list" approach to both identifying problems and proposing solutions. With problems, this often takes the form of lists of issues (sometimes long lists) that are presented as separate items. There is little apparent consideration for how the issues might be related, perhaps as parts of a larger issue, and little apparent effort to organize the list. With solutions, this often takes the form of a list of suggestions, again presented as separate items with little apparent consideration for the relationships that might exist among the suggestions. In both cases, the result is a piecemeal collection of ideas that lacks apparent coherence or coordination. 
Example: One student's analysis of a case included the following list, with no discussion or attempt to organize the list:

- Lack of time to go through the modules

- Lack of updated computer system

- Lack of proper maintenance

- Lack of appropriate and comprehensive design

- Lack of relevancy

- Lack of positive attitudes

- Lack of administrative support

- Lack of dedicated place for going through the modules

- Lack of qualified personnel to administer the modules

- Lack of leadership

- Lack of effective award system

\section{Levels of commitment (tentative vs. firm)}

Both novice and expert problem solvers are solution oriented and often propose solutions early in the problem-solving process. However, they will do this in different ways. Experts recognize that the available information is incomplete and that there are multiple ways to address the different issues (LeMaistre, 1998). As a result, they are likely to take an advisory tone when making suggestions (you might', perhaps you could...). They are more likely to take an empathic position, explaining possible reasons behind the actions of the key players in the case. And they are more likely to modify or eliminate proposed solutions when new information becomes available.

Example: "She meant well, but her grading policy and requirement may be outside of the students' ability and willingness to commit for the course. . . What I don't understand is that the course is a required junior/senior level course in a prestigious university, which indicates to me potentially a strong background of students. So maybe it's not a mismatch."

In contrast, novices often propose solutions in a dictatorial manner (you must ..., you should ...). They are likely to take a judgmental position, often criticizing or finding fault with one or more key players in the case. In addition, once proposed, their suggestions are often "carved in stone." As new information becomes available, novices tend to stand by their original suggestions. Rather then modifying their suggestions, they often find ways to justify them in spite of the new information.

Example: "The agency must develop a program that is centered around forecasting. The time that is spent navigating through the other modules takes unnecessary time away from the forecaster's responsibilities. The modules that are in place now simply are a waste of precious time."

5. Implications of recommendations (broad focus vs. narrow focus)

Both novices and experts frequently suggest solutions to the problems identified in a case. Experts typically think through their suggestions, explicitly considering how those suggestions might be implemented and/or what effects they might have (Rowland, 1992). In addition, their consideration of impact/implications is broader. It often goes beyond a straight-line focus on a problem and its immediate solution to consider other issues that may be important (e.g., cost, time, reactions of key players).

Example: "One format of the formative evaluation that could be considered is to randomly select ten percent of the employees at each of the nine plants and request their anonymous, confidential participation. This format would be relatively expensive due to the number of sites and facilitators required. A modified version of this format is to randomly select ten percent of the employees from one site to conduct the FE. This version would allow Ronda to conduct the FE without training other facilitators. While the cost would be lower, the depth of information would not be as great. Some biases also might be present that could influence the quality of the results. These results would not be considered representative of all plants."

In contrast, novices make suggestions without apparent regard for how those suggestions might be implemented or what effects they might have. That is, novices typically do not include overt consideration of impact and implications in their write-up of a case. When they do consider impact/implications, it is limited to a narrow focus on resolving the identified problem. This takes the following form: The problem is ... What I would do is . . That would solve the problem by ...

Example: "I would have each group meet outside of class to discuss any problem or misunderstanding of the lab ... for further class I would recommend that Sandra start to raise money for the department. She can do this by holding fund raisers. Also she can ask companies if they can donate equipment for an exchange of volunteer work for their company." 